BLS 34, No 1 2008. DOI: http://dx.doi.org/10.3765/bls.v34i1.3565

(published by the Berkeley Linguistics Society and the Linguistic Society of America)

\title{
Reflexives and the Shift between First and Second Person: The Case of Japanese ${ }^{1}$
}

OSAMU ISHIYAMA

Ball State University and University at Buffalo - SUNY

\section{Introduction}

The shift of person categories is not uncommon in the world's languages. In particular, it is widely observed that third person forms have come to be used as second person forms in some European languages for the purpose of politeness. For example, German uses the third person Sie as a polite second person pronoun. Similarly, Spanish polite second person pronoun usted comes from the nominal form vuestra merced 'your grace' which is formally a third person form. The same type of development is suggested for pronouns from other languages, such as Portuguese você (from Você Mercê 'your grace') and Italian lei (from la vostra Signoria 'your lord') (Mühlhäusler and Harré 1990). A similar situation holds for Asian languages such as Thai, Burmese, and Vietnamese where lexical nous 'servant' and 'lord' are used for the first and second person, respectively.

In Japanese, it is argued that the shift of person categories is not limited to the cross-linguistically common shift from the third to first/second person. The shifts from the first to second person as well as from the second person to first person are reported (Whitman 1999, Shibasaki 2005). Consider the following examples.

(1) [from first person to second person]

a. (Kojiki, 712) (Whitman 1999:358)

koto-na-gusi we-gusi ni ware wehinikeri

matter-none-sake laugh-sake on ware got.drunk

'On that blameless sake, that laughing sake, I (ware) got drunk.'

b. (Uji Shui Monogatari, 1218) (Whitman 1999:358)

ware ha miyako no hito ka. iduko he ohasuru zo.

ware TOP capital GEN person Q where to go.HON EMPH

'Are you (ware) from the capital? Where are you going?'

\footnotetext{
${ }^{1}$ I am grateful to David Fertig, David Zubin, and Mitsuaki Shimojo for their valuable comments. All errors are mine.
} 


\section{Osamu Ishiyama}

(2) [from second person to first person]

a. (Genji Monogatari, Miyuki, 1002)

"Naishi-no-Kami ni, ore wo, mooshiinashi tamahe." mistress.of.staff DAT ore ACC put.up RESP 'Put me (ore) up for Mistress of Staff.'

b. (Koshoku Ichidai Otoko, Book 6, 1682)

Ore wa kurumi-ae no mochi o aku hodo. ore TOP walnut-dressed GEN rice.cake ACC get.tired extent 'I (ore) want to eat rice cake dressed with walnuts to my heart's content'

(1) illustrates a case of the shift from the first to second person, whereas (2) exemplifies a shift from the second to first person. Previous studies also note that the shift from the first to second person is much more common that the shift from the second to first person.

This study argues that the forms that underwent the shift between the first and second person are actually reflexives or markers of self, thus the alleged shift should be simply seen as the first or second person interpretation of reflexives. The rest of this paper is organized as follows. Section 1 briefly discusses the previous approach to the problem and its problems. The approach of this study is described in Section 2. Section 3 presents a case study. Finally, Section 4 discusses some implications of this study.

\section{Whitman's Approach}

This section briefly describes Whitman's (1999) approach to the shift and its problems. Whitman (1999) presents an explanation based on the notion of empathy and direct discourse perspectives formulated in the works of Kuno (see for example Kuno 1972, 1987, 2004, Kuno and Kaburaki 1977). Whitman argues that the shift between the first and second person (or intrapersonal pronoun shift, as he calls it) is motivated by reflexive functions in the so-called long-distance binding or logophoric context. Kuno's studies show that Japanese reflexives in the logophoric context are represented as first or second person pronouns in direct discourse representations. For example, the reflexive jibun as the subject of the complement clause in the Modern Japanese equivalent of John said that he (jibun) is a genius will be replaced by a first person pronoun in its direct discourse representation, the equivalent of John said, "I am a genius." Whitman suggests that this line of explication may extend beyond the logophoric context and argues for the directionality of shift from pronouns to reflexives as well as from reflexives to pronouns. He argues that this is how reflexives have come to be reanalyzed as first or second person pronouns. In other words, intrapersonal pronoun shift is mediated by pronouns used reflexively. Although the notion of reflexive and empathy, as we will see below, are important in this study too, it is hard to see how his approach can explain the whole range of phenomena associated with shift of person categories. The following issues pose problems for his approach: (i) the fact that the shift from the first to second person is more 


\section{Reflexives and the Shift between First and Second}

common that the shift from the second to first person is left unexplained, (ii) not all instances of the shift involves the long-distance binding context even in the stage when the shift supposedly started and the directionality of the shift (especially the shift from pronouns to reflexives) is hard to be motivated, and (iii) Whitman notes that it is difficult to decide the original function of some forms definitively (i.e. a first/second person pronoun or a reflexive).

\section{Approach of this Study}

In the previous section, Whitman's (1999) approach regarding the shift of person categories or what he calls intrapersonal pronoun shift (i.e. shift between the first and second person category) as well as its problems were discussed. His claim is problematic in the following areas: (i) the fact that the shift from the first to second person is more common than the shift from the second to first person is left unexplained, (ii) the context in which the shift occurs and its directionality, and (iii) difficulty to determine the original person category of some forms. In light of these observations, the present study employs a similar, but somewhat different approach to the shift of person categories. Whitman's approach states that first and second person forms undergo the shift when they are used reflexively in the logophoric context. This study, on the other hand, argues that items that supposedly went through the shift of person categories are not semanticized first/second person pronouns, but simply reflexives or markers of self. In fact, some researchers have pointed out that there is no need to treat the so-called personal pronouns and reflexives separately at least in Pre-Modern Japanese. For example, in his grammar of classical Japanese, Vovin classifies personal pronouns and reflexives as a single category, using the term personalreflexive pronouns because "in the language of Classical Japanese prose most of them can be used in both functions" (2003:97). Therefore, under this approach, the shift of person categories is not mediated by the reflexive function in the longdistance binding context as is the case with Whitman's (1999) approach, but explained within the scope of normal reflexive behaviors. That is to say, being morphologically invariant, Japanese reflexives can be used for any person category given the right context. The so-called personal pronoun function is a reflection of pragmatic interpretation of reflexives as having first and second person referents, which may or may not semanticize. This approach of treating the items that underwent the shift of person categories as reflexives also has the advantage of handling the issues that arose from Whitman's (1999) approach.

The first issue to be discussed is that of scarcity of the shift from the second to first person compared to the shift from the first to second person. Previous studies have observed that the shift from the first to second person is much more common than the other way round. However, the problem is simply mentioned, but largely left unexplained. The root of the problem seems to lie in the fact that Whitman (1999) argues that the shift from pronouns to reflexives is possible, in addition to the expected 'shift' from reflexives to pronouns (i.e. pronoun interpretation of reflexives). Under the approach of this study, on the other hand, the forms in 


\section{Osamu Ishiyama}

question are reflexives in the first place that give rise to pragmatic interpretation of the first and second person. As mentioned above, semanticization of this pragmatic interpretation is a possible, but not a necessary consequence. Therefore, I claim that the question that needs to be asked is not "why is the shift from the first to second person more common than the shift from the second to first person?, but 'why are reflexives interpreted as the first person more often than as the second person?' I argue that the answer to this question lies in the notion of empathy (e.g. Kuno 1987, 2004, Kuno and Kaburaki 1977). In his series of influential works (see Kuno 2004 for a concise summary), Kuno proposes the notion of empathy and various empathy hierarchies. ${ }^{2}$ He defines empathy as "the speaker's identification, which may vary in degree with a person/thing that participates in the event or state that he/she describes in a sentence" (2004:316). Although Kuno proposes several hierarchies, the one particularly relevant to this study is the speech act empathy hierarchy which states that it is easiest to empathize with the speaker. The notion of empathy can be applied to answer the question raised above, namely 'why do reflexives get pragmatic interpretation of the first person more often than the second person?' Reflexives, especially syntactically unbound ones that is in the subject position, tend to be interpreted as first person because they are both high in empathy. Situations under which reflexives are given the second person interpretation are usually limited to such circumstances as questions and orders. It is natural that reflexives used in questions and orders are pragmatically intended for the second person for epistemological reasons: it is much more common to ask questions for or give orders to the addressee than anyone else.

The second issue concerns the context in which the so-called shift occurs and its directionality. The contexts in which the shift is observed are more diverse than the ones demonstrated by Whitman. Not all instances of the shift involve the logophoric context. Recall Whitman's own example in (1b) where ware which is said to have shifted from the first to second person is used for the second person without involving the logophoric context. Some might argue that (1b) represents the usage after the shift has already completed. However, this argument faces difficulty because the example is from the time when the shift started according to Whitman. The approach of this study, on the other hand, is unaffected by this problem, because it does not consider a particular syntactic context as a source of the phenomenon in question. As we will see below, Japanese reflexives can be used in a wide range of contexts. In addition to the canonical locally bound reflexives and the ones in the logophoric context (i.e. long-distance binding context), syntactically unbound reflexives are not uncommon in discourse.

The third and last issue to be discussed is indeterminacy with respect to the original category of the item that underwent the 'shift'. Whitman (1999) notes that the original person category cannot be shown definitively for some forms.

\footnotetext{
${ }^{2}$ Whitman also discusses empathy, but his argument is largely in conjunction with long-distance binding contexts.
} 


\section{Reflexives and the Shift between First and Second}

This question turns out to be the easiest to deal with under the approach of this study. Person categorical indeterminacy is expected from the beginning, because it maintains that the items in question are reflexives which are unspecified for person categories.

Based on the discussions of the present section, the next sections will examine diachronic development of temae '(lit.) in front of hands' which has been presented in previous studies as a case of intrapersonal pronoun shift (cf. Whitman 1999, Miwa 2000, 2005, Shibasaki 2005).

\section{Case of Temae 'in front of hands'}

Morphologically, temae consists of te 'hand' and mae 'front', and according to comprehensive dictionaries such as Nihon Kokugo Daijiten (Nihon Daijiten Kankokai 1972-1976), various nominal uses of temae are attested since the 12th century. In a literal sense, it meant 'in front of the speaker' or 'the area that is close to the speaker', but the extended uses such as 'one's skill (especially in the context of martial arts and tea-making)' and 'one's economic situation' were also attested.

Its use for person referents, on the other hand, is found primarily since the 17 th century. It has been presented in previous studies such as Shibasaki (2005) as a form that shifted its category from the first to second person. However, this study argues that this view needs to be reexamined because the present study maintains that forms that underwent the alleged shift are actually reflexives. Therefore, it is expected that it can be used for both first and second person referents. Consider the following examples.

(3) [temae for first person] (Yotsuya Kaidan, Act 5, 1825)

Sate sate fuugana jyuukyo jya na. Iya, temae koto wa, well well elegant house COP FP um temae thing TOP kono atari ni jyuukyo itasu $\quad$ mono
this neighborhood in reside

'Well, well, it is an elegant house. I (temae) also reside in the neighborhood, but ....'

(4) [temae for second person] (Yotsuya Kaidan, Act 3, 1825)

...Sorya o-temae, kore made nengoroni shita kahi ga nai toiumono. then HP-temae this until closely did worth NOM not.exist COMP 'Well, if you (temae) say so, that would make our close relations up until now useless.'

As you can see in the above examples, temae is used for the first person in (3), but for the second person in (4). In (3) the speaker, in search of his missing hawk, refers to himself as temae in conversation with a woman at her house. In (4), on 


\section{Osamu Ishiyama}

the other hand, the speaker calls the addressee temae when responding to the remark made earlier by the addressee who indirectly asked for money from the speaker. Considering this indeterminacy with respect to person category and the fact that these examples are from the same text, it seems that the position of this study that temae is not a pronoun of a particular person category, but a reflexive unspecified for person is a more likely scenario than the view that temae was originally a first person form and later became a second person form. It should also be noted that temae is syntactically unbound in both examples.

The basic use of temae as a reflexive does not seem to change in Modern Japanese either where the form is generally considered as a second person pronoun. Consider the following examples.

a. [temae for first person] (Neko, Chapter 9, 1905)

"Doomo soo, go-kenson de wa osoreiru.

well such HP-modesty COP TOP sorry

Kaette temae ga itamiiru."

on.the.contrary temae NOM be.ashamed

'Well, I feel sorry if you are being modest like that. It would make me (temae) feel ashamed.'

b. [temae for second person] (Botchan, Chapter 4, 1906)

Temae no warui koto wa warukatta to it-teshimaw-nai-uchi temae NOM wrong thing TOP was.wrong COMP say-ASP-NEG-until

wa tsumi wa kie-nai mon da.

TOP guilt TOP vanish-NEG thing COP

'You guys, I thought to myself... Until you acknowledge that what you (temae) did was wrong, you're still guilty in my eyes.'

In (5a) the speaker designates himself as temae when he tries to persuade his friend's uncle to sit in the better part of the room (close to tokonoma 'alcove'). In (5b), thinking about the prank his students did to him, the protagonist teacher refers to his students as temae. Again, temae in the above examples is syntactically unbound.

However, contrary to the claim of this study that temae is a reflexive, it is the intuition of contemporary speakers that temae is a derogatory second person pronoun. Where does that intuition come from, since it can be used for both first and second person, as we saw above? I argue that the intuition comes from the Present-Day Japanese use of temae where it is mostly used as a derogatory term for the addressee, and the intuition of contemporary speakers is reasonable in that the item is usually pronounced as temee with some phonological weakening in 


\section{Reflexives and the Shift between First and Second}

Present-Day Japanese. It is not pronounced in this way when temae is given the first person or spatial interpretation, which opens the possibility that at least temee (phonologically reduced version), not temae, has semanticized as a contemptuous second person form.

\section{Conclusion and Implications}

In this paper, I argued that forms that allegedly underwent the shift between the first and second person should be seen as reflexives unspecified for a person category. This approach can account for why the 'shift' from the first to second person is much more common: both reflexives and first person pronouns are high in empathy, which makes the first person use or interpretation more frequent. There is another important issue to which the approach of this study can offer a possible solution. Some previous studies have suggested that there is a necessary connection between the shift of person categories and pragmatic depreciation of the item. That is to say, when the item shifts from the first to second person, it loses some politeness value toward the addressee. For example, Miwa (2000, 2005) proposes that pragmatic depreciation arises as a result of using a first person form which is associated with the speaker's self-belittlement or selfassertion for a second person referent. However, since he does not give a detailed account of his suggestion, it is not immediately clear how things of the opposite nature, namely self-belittlement and self-assertion, can yield the same effect of pragmatic depreciation. Similarly, Shibasaki (2005) claims that there is a necessary connection between the shift of person categories and pragmatic depreciation. In particular, Shibasaki argues that first person forms never shift to second person forms without pragmatic depreciation. His argument can be illustrated in the following example in which ware is used for both first and second person.

(6) [ware for first and second person] (Amakusa Isopo Monogatari, 16C)

(Shibasaki 2005:172)

Isopo ga iu ni wa "Ware wa ningen de gozaru". Isopo NOM say to TOP ware TOP human COP POL

Shanto ayasyuu iwa-ruru wa

Shanto suspiciously say-HON TOP

"Ware ni sore woba towa nu..."

ware to that ACC ask NEG

'Isopo said that, "I (ware) am mankind. " Shanto suspiciously said, "I don't ask you (ware) such an obvious thing."”

The first ware is used for the first person, and since it occurs with the polite marker gozaru, its use is not disrespectful for the addressee. The second ware, on 


\section{Osamu Ishiyama}

the other hand, is used for the second person, and its use is not polite, if not disrespectful, as can be seen in the lack of polite forms. Shibasaki presents (6) as a transitional example that captures the shift form the first person to second person as well as pragmatic depreciation that accompanies it. At first glance, it looks like the example conforms to his argument. However, it is not obvious why one should look at the above example as a case where a semanticized personal pronoun is being used for different person categories, since person categorical indeterminacy can be explained more naturally under the assumption that the item is not semanticized for a particular person category in the first place (i.e. reflexives). Additional evidence against the claim that there is a necessary relation between the shift of person categories and pragmatic depreciation comes from examples like (1) presented earlier where ware is used for the second person without pragmatic depreciation. That $(1 \mathrm{~b})$ is addressed to a social equal's wife and that the humble form of the verb 'to say' is used suggest that ware, even though it is used for the second person, is not derogatory or 'lowering' (cf. Whitman 1999). These examples show that the so-called shift does not have to be accompanied by pragmatic depreciation.

Although there is no necessary connection between the shift and pragmatic depreciation, it is generally the case that many post-shift second person uses carry derogatory sense. The reflexive analysis can offer a possible solution to this problem too. Since this study maintains that the so-called shift is a reflection of reflexives being interpreted pragmatically as the first or second person depending on the context, the question to be asked within the present framework is: "why is the second person interpretation of reflexives often derogatory?' Although the approach of this study does not predict that there is a necessary or inherent relation between the second person use of reflexives and pragmatic depreciation, it is able to offer an explanation as to why the second person use can be or come to be perceived to be derogatory. From the perspective of this study, the derogatory status of the second person interpretation is due to the discourse behavior of reflexives. Zubin, Chan, and $\mathrm{Li}$ (1990), and $\mathrm{Li}$ (1991) have demonstrated that reflexives in languages like Mandarin and Korean can be used to indicate self-objectification or self-reflection in discourse. The same can be said about the Japanese reflexive. Consider the following example where the syntactically unbound reflexive jibun is used for self-objectification.

(7) [unbound jibun for self-objectification] (Botchan, Chapter 6, 1906)

a. Gakkoo no shokuin ya seito ni kashitsu no aruno wa, school GEN staff and student LOC mistake GEN exist TOP

b. minna jibun no katoku no itasu tokorode, all self GEN lack.of.virtue NOM do CONJ

nanika jiken ga aru tabini, some incident NOM exist every.time 


\section{Reflexives and the Shift between First and Second}

c. jibun wa yoku korede koochoo ga tsutomaru kato self TOP well this principal NOM can.serve COMP

hisokani zanki no nen ni taen ga, secretly shame GEN feeling DAT cannot.stand but

d. fukoonishite konkai mo mata kakaru soodoo o hikiokoshitano wa, unfortunately this.time also again like.this trouble ACC cause TOP

e. fukaku shokun nimukatte shazaishi nakerebanaran. [...]

deeply you facing apologize must.do

(a) As for the mistakes of school staff and students, (b) (they) are all the result of self's (jibun $=$ my) lack of virtue, and every time there are some troubles, (c) self (jibun = I) secretly cannot help feeling the sense of shame that how (I) can serve as a principal like this, and (d) unfortunately, for the fact that (students) have again caused a trouble like this, (e) (I) must apologize to you sincerely. [...]

(7) is uttered by the principal of a school (where the protagonist has just started working) at the teachers' meeting. The teachers are discussing mischief that some students have conducted in order to harass their newly arrived teacher from Tokyo (the protagonist). There are two instances of syntactically unbound jibun, one in (b) and the other in (c). It should be noted that in both instances, although the principal is speaking in front of other teachers, he gives the impression that the utterance is addressed not to other teachers, but to himself. In fact, the entire utterance is in a self-reflective state. This is shown by the striking fact that the speaker uses the first person deixis only twice and both of them are realized as a reflexive. By choosing a reflexive instead of personal pronouns whose function is to designate an entity as someone who is present in the speech situation, the school principal successfully achieves the rhetorical effect of self-reflection. If first person pronouns were used in (7), the sense of self-reflection would be lost. In other words, reflexives in (7) are used to objectify the speaker in his thought/speech. This clearly parallels the use of reflexives for self-objectification or in a self-reflective state in discourse that Zubin et al. (1990) and Li (1991) have demonstrated with regards to Mandarin and Korean. Generally speaking, if events are told from the perspective of someone, it is most likely to be from that of the speaker since obviously the speaker is most accessible to himself/herself. Because empathy is the speaker's identification with someone or something, it is easier for the speaker to empathize with himself/herself than with any other entity in the discourse.

What about reflexives for the second person? Li (1991:143-145) shows that syntactically unbound Mandarin reflexive ziji in interactional discourse can 


\section{Osamu Ishiyama}

function as an indication that the speaker is 'thinking for' the addressee or 'leading the addressee's thought'. This is illustrated in the following example.

(8) [Chinese reflexive ziji for 'leading addressee's thought'] (Li 1991:143-144)

a. Ni xiangxiang kan, zai zher gan xiaqu you shenmo yisi ne? you think see at here work continue there.is what meaning FP

b. Zhe huor you lei, gongzi you di, this job also tire salary also low

c. ziji nianling you zhemo da le, self age also so old FP

d. zaodiar tuixiu zai jia bao sunzi duo hao a! early a.little at home hold grandson so.much good FP

'(a) Think about it, what's there (to self) to continue working there? (b) The work load is heavy, and the pay is low, (c) and self (ziji = you) is already so old; (d) how much more fun it would be to retire a little early and play with (self's) grandson at home! ..."

In the above example, the speaker is trying to persuade the addressee to retire from work. In doing so, the speaker empathizes with or takes the perspective of the addressee with the use of reflexive rather than a second person pronoun. $\mathrm{Li}$ (1991: 144) points out that the speaker is trying to think in the way addressee would think or in the way the speaker hopes the addressee would think. This is done through the use of reflexives which present an entity as someone who should be seen objectively rather than personal pronouns which highlight the status of an entity as someone who is present in the current speech situation. In other words, the speaker is thinking in a self-reflective mode for the addressee or inducing $\mathrm{him} /$ her to self-reflect. This use of reflexives in interactional discourse is what $\mathrm{Li}$ calls "leading the addressee's thought". It seems that this mechanism can be extended to a different function, namely sarcasm or criticism. By leading the addressee's thought, the speaker is able to induce the addressee to evaluate his/her thought/action objectively, thus being pragmatically perceived as a sort of criticism/sarcasm by the addressee. Therefore, in this context too, the referent of reflexive is necessarily non-first person. Consider the following example.

(9) (Yotsuya kaidan, Act 5, 1825)

Hiite kaera ba, saa kisama ga hik-e. Iya temae hiite ik-e. pull return if EXCL you NOM pull-IMP no temae pull go-IMP 'If you are telling me to go back, you pull the leash of the dog. No, you (temae) pull it and go!' 


\section{Reflexives and the Shift between First and Second}

In (9) the speaker is clearly upset and bellicose, as can be seen in the use of imperatives. This example is particularly interesting in that the speaker first refers to the addressee by a second person pronoun kisama and later by a reflexive temae. According to the approach of the present study, this suggests that the speaker appeals to the addressee directly in the first half of the utterance by using the marker of the speech role of the addressee, and in the second half he is trying to lead addressee's thought or action by speaking of the way he hopes the addressee would act by the use of the reflexive. Or it is more appropriately characterized that the speaker is pushing the addressee to think and act in the way speaker wishes, thus the utterance gives the impression of criticism. This switch of an address term from a pronoun to a reflexive illustrates the dramatic effect of the derogatory use of a reflexive.

The account based on discourse behavior of reflexives does not state that there is a necessary relation between the post-shift second person use and pragmatic deprecation, since there is nothing inherently derogatory about empathizing with the addressee or taking the perspective of the addressee. For example, in (8) and (1b), Chinese ziji and Japanese ware are used for the second person in a nonderogatory way: see also (4) in which temae for the second person is modified by the polite prefix $o$-. However, the approach of this study is also able to offer a possible explanation as to why many instances of reflexives for the second person carry derogatory sense. It comes from their discourse use for leading the addressee's thought. Therefore, unlike previous studies such as Miwa (2000, 2005) and Shibasaki (2005) who argue for a necessary relation between the shift and pragmatic depreciation, this study can account for both derogatory and nonderogatory use for the second person.

\section{References}

Kuno, Susumu. 1972. Pronominalization, Reflexivization, and Direct Discourse. Linguistic Inquiry 3: 161-195.

Kuno, Susumu. 1987. Functional Syntax: Anaphora, Discourse, and Empathy. Chicago: University of Chicago Press.

Kuno, Susumu. 2004. Empathy and Direct Discourse Perspectives. In Lawrence Horn and Gregory Ward, eds., The Handbook of Pragmatics, 315-343. Malden, MA: Blackwell.

Kuno, Susumu, and Etsuko Kaburaki. 1977. Empathy and Syntax. Linguistic Inquiry 8: 627-672.

Li, Naicong. 1991. Perspective-Taking in Mandarin Discourse. Ph.D. diss., State University of New York at Buffalo.

Miwa, Masahi. 2000. Ninshoshi to keigo [Personal Pronouns and Honorifics]. Kyoto: Jinbunshoin.

Miwa, Masahi. 2005. Ichininsho nininsho to taiwa [First/second person and dialogue]. Kyoto: Jinbunshoin. 


\section{Osamu Ishiyama}

Nihon Daijiten Kankokai. 1972-1976. Nihon Kokugo Daijiten, 21 vols. Tokyo: Shogakkan.

Shibasaki, Reijirou. 2005. Personal Pronouns and Argument Structure: Discourse Frequency, Diachrony and Typology. Ph.D. diss., University of California, Santa Barbara.

Vovin, Alexander. 2003. A Reference Grammar of Classical Japanese Prose. New York: RoutledgeCurzon.

Whitman, John. 1999. Personal Pronoun Shift in Japanese: A Case Study in Lexical Change and Point of View. In A. Kamio, K. Takami and S. Kuno, eds., Function and Structure: In Honor of Susumu Kuno, 357-386. Philadelphia: John Benjamins.

Zubin, David, A., Soon Ae Chun, and Naicong Li. 1990. Misbehaving Reflexives in Korean and Mandarin. In Kira Hall, Jean-Pierre Koenig, Michael Meacham, Sondra Reinman, and Laurel A. Sutton, eds., Proceedings of the Sixteenth Annual Meeting of the Berkeley Linguistics Society, 338-352.

Berkeley: Berkeley Linguistics Society.

Osamu Ishiyama

Ball State University

Department of Modern Languages and Classics

North Quad 138

Muncie, IN 47306

oishiyama@bsu.edu

University at Buffalo - SUNY

Department of Linguistics

609 Baldy Hall

Buffalo, NY 14260

oi2@buffalo.edu 